ББК 63.4

\author{
Организация конференциии и издание материалов проведень \\ при финансовой поддержке Российского фонда фундаментальных исследований, \\ проект № 19-09-20008
}

Утверждено к печати Ученым советом ИИМК РАН

Редакционная коллегия тома I: В. А. Алёкшин, Л. Б. Кирчо (отв. редакторы),

В. П. Никоноров, В. Я. Стёганцева; В. В. Терёхина

Рецензенты: д. и. н. Л. Б. Вишняцкий, д. и. н. А. А. Выборнов

Программный комитет конференции: академик РАН, д. и. н., проф. М. Б. Пиотровский

(Государственный Эрмитаж, почетный председатель); д. и. н. В. А. Лапшин (ИИМК РАН, председатель); д. и. н. А. В. Головнёв (МАЭ РАН, сопредседатель); д. и. н. В. А. Дергачёв (Высшая антропологическая школа, Молдова, сопредседатель); д. и. н. И. Ф. Попова (ИВР РАН, сопредседатель); академик АН Республики Узбекистан, д. и. н., проф. Э. В. Ртвеладзе (сопредседатель); к. и. н. А. В. Поляков (ИИМК РАН, зам. председателя); к. и. н. В. А. Алёкшин (ИИМК РАН, зам. председателя); д. и. н. Ю. Е. Берёзкин (МАЭ РАН); Dr., Prof. Н. Бороффка (Германский археологический институт, Германия); В. С. Бочкарёв (ИИМК РАН); Dr. Э. Кайзер (Свободный университет Берлина, Германия); к. и. н. М. Т. Кашуба (ИИМК РАН); д. и. н. Л. Б. Кирчо (ИИМК РАН); к. и. н. А. В. Кияшко (Южный федеральный университет); к. и. н. П. Ф. Кузнецов (СГСПУ);

к. и. н. Н. М. Малов (СНИГУ); к. и. н. В. П. Никоноров (ИИМК РАН); Ю. Ю. Пиотровский

(Государственный Эрмитаж); д. и. н., проф. Д. Г. Савинов (Институт истории СПбГУ);

к. и. н. В. Н. Седых (Институт истории СПбГУ); к. и. н. Н. Н. Скакун (ИИМК РАН);

к. и. н. Н. Ф. Соловьёва (ИИМК РАН); к. и. н. А. И. Торгоев (Государственный Эрмитаж); к. и. н. Е. А. Черлёнок (Институт истории СПбГУ)

Организационный комитет конференции: к. и. н. А. В. Поляков (ИИМК РАН, председатель);

к. и. н. В. А. Алёкшин (ИИМК РАН, зам. председателя); В. С. Бочкарёв (ИИМК РАН); ); к. и. н. М. Т. Кашуба (ИИМК РАН); д. и. н. Л. Б. Кирчо (ИИМК РАН);

А. И. Климушина (ИИМК РАН, отв. секретарь); к. и. н. В. П. Никоноров (ИИМК РАН); Ю. Ю. Пиотровский (Государственный Эрмитаж); В. Я. Стёганцева (ИИМК РАН); В. В. Терёхина

(ИИМК РАН, МАЭ РАН, отв. секретарь); к. и. н. Е. С. Ткач (ИИМК РАН); И. Ж. Тутаева (Государственный Эрмитаж); к. и. н. Е. А. Черлёнок (Институт истории СПбГУ)

Древности Восточной Европы, Центральной Азии и Южной Сибири в контексте связей и взаимодействий в евразийском культурном пространстве (новые данные и концепции): Материалы Международной конференции, 18-22 ноября 2019 г., Санкт-Петербург. Т. I. Древняя Центральная Азия в контексте евразийского культурного пространства (новые данные и концепции). К 90-летию со дня рождения патриарха евразийской археологии Вадима Михайловича Массона. - СПб.: ИИМК РАН, Невская Типография, 2019. — 291 с.

ISBN 978-5-907053-34-2

DOI 10.31600/978-5-907053-34-2 


\title{
METAL “RODS” AND THEIR PURPOSE \\ (ACCORDING TO DATA FROM ARCHAEOLOGICAL SITES \\ OF CENTRAL ASIA OF THE $4^{\mathrm{TH}}-2^{\mathrm{ND}}$ MILLENNIA BC)
}

Farhod A. Razzoqov

Russian-Tadjik University, Dushanbe, Tajikistan

Keywords: archaeology, Central Asia, Paleometal Age (4th-2nd mil. BC), grave complex, metal "rod", tool assignment issues.

Thanks to the study of ancient agricultural monuments of Central Asia, many, but not all, features of the development of the culture of local communities were clarified. Currently, scholars are trying to give a new interpretation to a number of products of material culture (in this case, metal "rods") compared with their predecessors.

\section{ПАРНЫЕ НЕОДНОВРЕМЕННЫЕ ПОГРЕБЕНИЯ ЮЖНОГО УРАЛА И СРЕДНЕЙ АЗИИ: СРАВНИТЕЛЬНАЯ ХАРАКТЕРИСТИКА ${ }^{1}$}

\author{
Я. В. Рафикова \\ Институт истории, языка и литературы Уфимского федерального исследовательско- \\ го иентра РАН, Уфа, Россия
}

DOI: $10.31600 / 978-5-907053-34-2-88-91$

Ключевые слова: неодновременные парные погребения, алакульская культура, тазабагъябская культура, бишкентско-вахшская культура.

Неодновременные парные разнополые погребения, где покойники уложены «лицом друг к другу», исследованы в могильниках эпохи поздней бронзы Южного Урала (алакульская) и Средней Азии (тазабагъябская и бишкентско-вахшская культуры). В этих культуpax количество упомянутых захоронений относительно сопоставимо: в алакульских - 10, в тазабагъябских - 7, в бишкентско-вахшских - 6 (Рафикова 2018; Итина 1961; Виноградов и др. 1986; Мандельштам 1962; Пьянкова 1987).

Рассматриваемые погребения можно разделить на три варианта в зависимости от состояния останков ранее захороненного индивида: в сочлененном состоянии и полном порядке (вариант 1); частично нарушены (вариант 2); полностью нарушены и представляют собой груду костей (вариант 3) (Рафикова 2018: 53).

Погребения варианта 1 представлены только в алакульской и бишкентско-вахшской культурах. В единственном алакульском погребении (Ново-Аккермановка 4) подхороненная женщина лежит на груди, лицом вниз, с повернутыми вправо ногами, ранее захороненный мужчина располагался скорченно, на левом боку (рис. 1, 1). В бишкентско-вахшских погребениях (Ранний Тулхар, мог. 20; Ой Куль, мог. 6) тело подхороненного покойника уложено в могилу над останками ранее погребенного усопшего, практически полностью перекрывая их (рис. 1,2). В этих погребениях мужчины лежали на правом боку, а женщины на левом. И в алакульском, и в бишкентско-вахшских захоронениях первыми похоронены мужчины.

\footnotetext{
${ }^{1}$ Работа выполнена в рамках подпрограммы «Памятники материальной и духовной культуры в современной информационной среде» (I.25) проект № 255 «Парные разнополые погребения эпохи бронзы от Урала до Индостана как источник по реконструкции семейно-брачной и социальной структуры» программы Президиума РАН «Социально-гуманитарные аспекты устойчивого развития и обеспечения стратегического прорыва России» и государственного задания ИИЯЛ УФИЦ PAН на 2019 г.
} 
Вариант 2 представлен во всех культурных группах. В двух алакульских погребениях у ранее захороненных покойников сдвинуты кости голеней (Тасты-Бутак 1, оградка 43; Ташла-1, 2/11). В тасты-бутакском погребении на левый бок положен мужчина, на правый - женщина, похороненная ранее (рис. 1, 3).

Во всех тазабагъябских погребениях останки ранее погребенных находятся в относительном порядке, нарушения их минимальны, сдвинуты с места в основном кости верхних

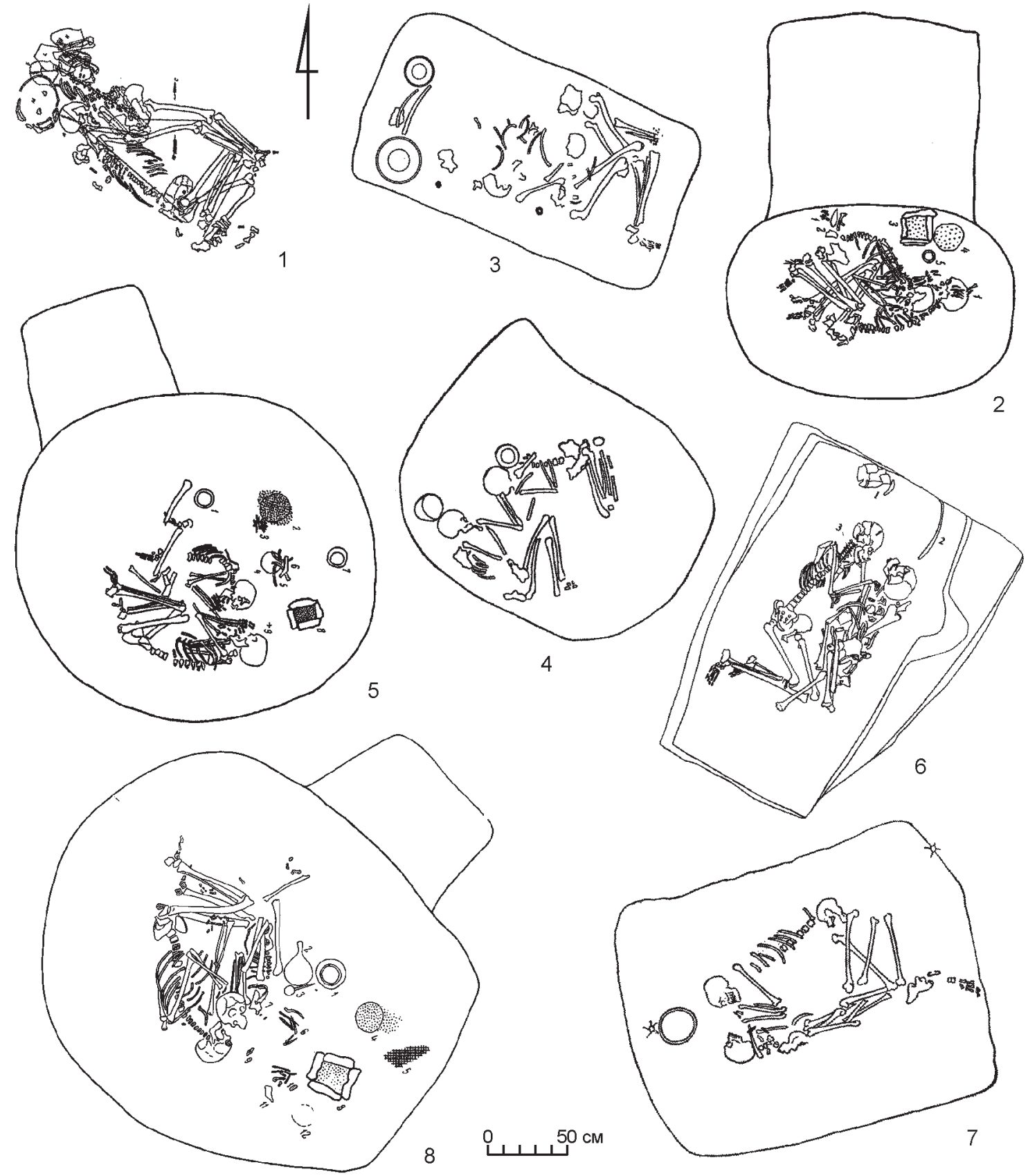

Рис. 1. Парные неодновременные разнополые погребения: 1, 2 - вариант 1; 3-5 - вариант 2; 6-8 - вариант 3. 1 - Ново-Аккермановка, погребение оградки 4 (по: Подгаецкий 1940: рис. 7); 2, 5, 8 - Ранний Тулхар, мог. 20, 25, 43 (по: Мандельштам 1968: рис. 8, 11, 22); 3 - Тасты-Бутак 1, погребение оградки 43 (по: Сорокин 1962: табл. XXVII); 4, 7 - Кокча 3, погр. 79 и 24 (по: Итина 1961: рис. 13, 2 и 6, 5); 6 - Березовский V, кург. 6, погр. 1 (по: Федоров, Рафикова 1996: рис. 2) 
и нижних конечностей. В Кокча 3 (погр. 79) останки подхороненной женщины находились на 20 см выше останков мужчины (рис. 1,4). В этих захоронениях на правый бок положен мужчина, а на левый - женщина. В двух погребениях первым был похоронен мужчина (Кокча 3, погр. 23 и 79), в одном - женщина (Кокча 3, погр. 84).

В единственном в этой группе бишкентско-вахшском захоронении (Ранний Тулхар, мог. 25) останки подхороненного позже мужчины находятся на 7-8 см выше уровня женского скелета, у которого смещены и сломаны кости ног (рис. 1,5 ).

Вариант 3 представлен шестью алакульскими захоронениями, четырьмя тазабагъябскими и двумя бишкентско-вахшскими.

В алакульских погребениях останки ранее захороненного покойника представлены компактной грудой костей (рис. 1, 6). Видимо, скелетированные останки ранее захороненного покойника при подхоронении второго усопшего были вынуты, а затем сложены обратно. Половая принадлежность усопших в одном случае неясна. В четырех случаях останки мужчины находились справа от женщины (в одном - на правом боку и в трех - в виде груды) и только в одном случае - слева от нее, на левом боку. Соответственно останки женщины располагались слева от мужчины в четырех случаях (в трех - на левом боку и в одном - в виде груды) и в одном случае - справа от мужчины в виде груды. В трех случаях ранее захоронен мужчина, в двух - женщина.

В тазабагъябских погребениях этого варианта останки ранее захороненного покойника просто сдвигали в сторону. Вероятно, в некоторых случаях отдельные кости, мешавшие укладыванию второго покойника, вынимали, а потом помещали обратно (рис. 1,7). Правило положения на левом боку женщины, а на правом - мужчины строго соблюдено и здесь. В большинстве случаев (3) ранее была захоронена женщина и только в одном случае мужчина.

В двух бишкентско-вахшских погребениях этого варианта (Макони Мор, погр. 33 и Ранний Тулхар, мог. 43) кости ранее погребенного смещены при подхоранивании второго покойника (рис. 1, 8). В обоих случаях первой была похоронена женщина, положенная на левый бок.

Несомненные признаки сходства отмечаются в тазабагъябской и бишкентско-вахшской выборках: 1) разноуровневые захоронения в варианте 2; 2) сходное обращение с останками ранее захороненного покойника (сдвигание костей), особенно в варианте 3 ; 3) во всех погребениях на левом бок положена женщина, на правый - мужчина; 4) преобладание подхоронения мужчин к ранее погребенной женщине в тазабагъябской культуре незначительное (4 против 3), а в бишкентско-вахшской культуре уже существенное (3 против 1).

Алакульские неодновременные погребения несколько отличаются от центральноазиатских, но всё же невозможно не отметить и черты сходства. Здесь также представлены захоронения, где к ранее погребенным женщинам подхоронены мужчины. Примечательно положение женщин на левом боку в большинстве погребений варианта 3. Для алакульских парных захоронений такое положение женщин не характерно, а для центральноазиатских - норма.

Одним из возможных объяснений сходства обряда разновременного парного погребения в трех рассмотренных культурах, является наличие у них общего культурного компонента.

\section{Литература}

Виноградов А. В., Итина М. А., Яблонский Л. Т. 1986. Древнейшее население низовьев Амударьи. М.

Итина М. А. 1961. Раскопки могильника тазабагъябской культуры Кокча 3. М. (МХЭ. Вып. 5). 
Мандельштам А. М. 1968. Памятники эпохи бронзы в Южном Таджикистане. Л. (МИА. № 145). Подгаецкий Г. В. 1940. Могильник эпохи бронзы близ г. Орска // Третьяков П. Н. (ред.). Археологические памятники Урала и Прикамья. М.; Л. С. 69-81 (МИА. № 1).

Пьянкова Л.Т. 1987. К вопросу о семейных и общественных отношениях в эпоху поздней бронзы (по материалам могильников вахшской культуры) // Негматов Н.Н., Ранов В.А. (отв. ред.). Материальная культура Таджикистана. Душанбе. Вып. 4. С. 43-70.

Рафикова Я. В. 2018. Неодновременные парные погребения из алакульских могильников Южного Урала и Западного Казахстана // Рафикова Я.В. (отв. ред.). Мужской и женский мир в отражении археологии. Уфа. С. 50-62.

Сорокин В. С. 1962. Могильник эпохи бронзы Тасты-Бутак I в Западном Казахстане. М.; Л. (МИА. № 120).

Федоров В. К., Рафикова Я.В. 1996. Березовский V курганный могильник эпохи бронзы в Южном Зауралье // Акбулатов И. М. (отв. ред.). Башкирский край. Уфа. Вып. 6. С. 49-71.

\title{
PAIRED NON-SIMULTANEOUS BURIALS OF THE SOUTHERN URALS AND CENTRAL ASIA: COMPARATIVE CHARACTERISTICS
}

\author{
Yanina V. Rafikova \\ Institute of the History, Language and literature, Subdivision of the Ufa Federal Research Centre of \\ the Russian Academy of Sciences, Ufa, Russia
}

Keywords: paired non-siymultaneous burials, Alakul' culture, Tazabagyab culture, Bishkent-Vakhsh culture.

The rite of the non-simultaneous paired heterosexual burial has a stable tradition in the Alakul (Southern Urals), the Tazabagyab and the Bishkent-Vakhsh (Central Asia) burial grounds. An analysis of the burials according to the main indicators (the state of the remains of a previously buried dead person, his/her gender, and also the position of the deceased on one side or another, depending on his/her gender) shows the undoubted similarity of the Tazabagyab and Bishkent-Vakhsh non-simultaneous burials. The Alakul' non-simultaneous burials are somewhat different from the Central Asian ones, however, there are certain similarities with them: the burial of men to women and the position of women on the left side, and men on the right.

One of the possible explanations for the similarity of the ritual of the paired non-simultaneous burials in the three cultures considered is the presence of a common cultural component.

\section{КУЛЬТУРНЫЕ СВЯЗИ ИРАНА С СОПРЕДЕЛЬНЫМИ СТРАНАМИ НА ПРИМЕРЕ ТЕРРАКОТОВЫХ АНТРОПОМОРФНЫХ СТАТУЭТОК ГИЛЯНА В РАННЕМ ЖЕЛЕЗНОМ ВЕКЕ (І ТЫС. ДО Н. Э.) ${ }^{1}$}

\author{
К. Пеласаеиди \\ Университет культуры и искусства Ирана, Тегеран, Иран
}

DOI: 10.31600/978-5-907053-34-2-91-94

Ключевые слова: древний Иран, Гилян, ранний железный век, терракотовые мужские и женские статуэтки.

Область Гилян, расположенная на севере Ирана, была одним из центров развития древней культуры, о чем свидетельствует большое количество археологических памятников и уникальных артефактов. Среди них особое место занимают статуэтки, которые являются

\footnotetext{
${ }^{1}$ Перевод с персидского яз. Т. М. Бостановой.
} 